\title{
The Substitution Effect from the Profit Function in Consumption: Expressions from the Marshallian, Hicksian, and Frischian demand functions
}

\author{
José Ignacio Gimenez-Nadal* \\ University of Zaragoza, Zaragoza, Spain
}

Received: 21 May 2018

Revised: 03 September 2018

Accepted: 03 September 2018

\begin{abstract}
In the context of the optimizing behaviour assumption of individuals (Becker, 1976), three types of demand functions appear: Marshallian, Hicksian, and Frischian functions (Sproule, 2013). The Substitution Effect (SE) is a relevant concept, with our short paper developing two alternative theoretical expressions, specifically focusing on the Profit Function in Consumption and the Frischian functions. I address the fact that these demand functions with constant marginal utility of income play a very relevant role in the inter-temporal context.
\end{abstract}

Keywords: Demand analysis; Profit Function in Consumption; Substitution Effect; Marshallian, Hicksian and Frischian demand functions; intertemporal context.

JEL Classification Codes: D01, D11

\section{Introduction}

Sproule (2013) shows a systematic relationship among the Marshallian, the Hicksian, and the Frischian demand functions on the basis of the profit maximization hypothesis. By using this optimization approach, we now extend it providing alternative expressions of the Substitution Effect (SE) from the relationships among these three Marshallian, Hicksian, and Frischian demand functions. The SE is defined as the variation in the quantity demanded that results from an infinitesimal variation in the price of the corresponding or of a related good, in such a way that the utility or real income remains constant. In this way, the SE offers a real indicator (utility or real income constant) that is very useful in measuring the substitution phenomenon in the demanded quantity as a function of the price change. This indicator has received some attention in the empirical literature (see, for example, Ashenfelter and Heckman, 1974; Manoli and Weber, 2010; Altonji, 1986; Brandt et al., 2013), but few articles have examined its theoretical properties.

\footnotetext{
*E-mail: ngimenez@unizar.es.

Citation: Giménez-Nadal, J. I. (2018) The Substitution Effect from the Profit Function in Consumption: Expressions from the Marshallian, Hicksian, and Frischian demand functions, Economics and Business Letters, 7(3), 9297.
} 
In order to partially cover this gap, I develop two alternative theoretical expressions derived from the relationships among the Marshallian, Hicksian, and Frischian demand functions. Specifically, I focus on the Profit Function in Consumption and in its Frischian demand functions, according to which the demanded quantities in equilibrium depend on prices and the marginal cost of the utility (inverse of the marginal utility of income).

This marginal cost of the utility, and the consequent Frischian demand functions, play specifically a very relevant role in the intertemporal context. Given that a prime objective of individuals throughout the life cycle is to maintain constant their marginal utility of income, in such a way that future incomes do not reduce the utility contributions of such new incomes, the Frischian functions are particularly relevant in the consumption-saving topic. Thus, the decision of how much to consume and, consequently, how much to save, must be taken on the basis of the constancy of the marginal utility of income.

Additionally, this parameter (marginal utility of income) will have different treatments depending on if the intertemporal context is characterised by a certainty or an uncertainty environment. In the first case, certainty, the marginal utility of income will include, at the beginning of the life cycle, all the known and relevant extra-current information in the decision process and, consequently, it will not vary intertemporally. By contrast, an uncertainty context will introduce, period after period, new relevant information and, consequently, this new information will modify the parameter period by period along the life cycle.

The paper is organised as follows. In Section 2, I briefly describe the three optimization problems of the individual focusing on the SE. In Section 3, I provide alternative theoretical expressions of the SE, and Section 4 closes the paper with my main conclusions and the possible extensions of the work.

\section{Optimization problems}

The unitary approach to demand analysis studies the individual microeconomic decisions on the basis of the Ordinal Utility Theory, assuming that we do not distinguish between the individual agent and the collective agent (household) (Molina, 2011). In this context, the Primal Decision Problem consists of maximizing the Utility Function $\mathbf{u}(\mathbf{q})$, with $\mathbf{q}$ being the quantity vector, subject to the available income $y$, with $\mathbf{p}$ being the price vector:

$$
\operatorname{Max} \mathrm{u}(\mathbf{q}) \text { s.t } \mathrm{y}=\mathbf{p q}
$$

The maximum first order conditions of this Primal are:

$$
\begin{gathered}
\mathrm{u}_{\mathrm{i}}(\mathbf{q})-\lambda \mathrm{p}_{\mathrm{i}}=0 \quad(\mathrm{i}=1, \ldots, \mathrm{n}) \\
\mathrm{y}-\mathbf{p q}=0
\end{gathered}
$$

where $\mathrm{u}_{\mathrm{i}}(\mathbf{q})$ is the ith good marginal utility and $\lambda$ is the marginal utility of income. From these conditions, it is easy to derive the Marshallian demand functions $\mathrm{q}_{\mathrm{i}}=\mathrm{q}_{\mathrm{i}}(\mathbf{p}, \mathrm{y}),(\mathrm{i}=1, \ldots, \mathrm{n})$, which can be expressed in terms of expenditure, $c_{i}=p_{i} q_{i}=c_{i}(p, y)$, or in the budgetary distribution, $w_{i}$ $=\mathrm{p}_{\mathrm{i}} \mathrm{q}_{\mathrm{i}} / \mathrm{y}=\mathrm{w}_{\mathrm{i}}(\mathbf{p}, \mathrm{y})$.

The Dual Decision Problem consists of minimizing the cost, subject to a given utility level:

$$
\text { Min pq s.t } \mathrm{u}=\mathrm{u}(\mathbf{q})
$$

whose interior minimum first order conditions are:

$$
\begin{gathered}
p_{i}-\mu u_{i}(\mathbf{q})=0 \quad(i=1, \ldots, n) \\
u-u(q)=0
\end{gathered}
$$


where $\mu$ is the new Lagrangian parameter in this dual formulation, and from which we can derive the Hicksian demand functions: $\mathrm{q}_{\mathrm{i}}=\mathrm{h}_{\mathrm{i}}(\mathbf{p}, \mathrm{u}) \quad(\mathrm{i}=1, \ldots, \mathrm{n})$, with an important result being that the first derivative is the Substitution Effect:

$$
\mathrm{S}_{\mathrm{ij}}=\frac{\partial \mathrm{h}_{\mathrm{i}}}{\partial \mathrm{p}_{\mathrm{j}}} \quad(\mathrm{i}=1, \ldots, \mathrm{n})
$$

I now characterize a new type of demand function, the Frischian function, that is closely related to a different representation of preferences, the Profit Function in Consumption. This new representation, derived from the isomorphism existing between the consumption theory and the production theory, considers that the consumer uses some inputs, goods, to obtain an output, the utility. The Profit Function in Consumption constitutes a Dual representation of preferences, with the property that it perfectly maintains the inter-temporal separability of the utility function. That is to say, the fact that the utility throughout the life cycle can be assumed as the inter-temporal sum of the intra-temporal utilities can be extended to the Profit Function in Consumption. Given the Primal Decision Problem:

$$
\operatorname{Max} \mathrm{u}(\mathbf{q}) \quad \text { s.t } \mathrm{y}=\mathbf{p q}
$$

I can express the first order conditions as:

$$
\begin{aligned}
\mathrm{u}_{\mathrm{i}}(\mathbf{q})=\lambda \mathrm{p}_{\mathrm{i}} & =\frac{\mathrm{p}_{\mathrm{i}}}{\mathrm{r}} \quad(\mathrm{i}=1, \ldots, \mathrm{n}) \\
\mathrm{y} & =\mathbf{p q}
\end{aligned}
$$

where the Lagrange multiplier $\lambda$ is the income marginal utility $(\lambda=\mathrm{du} / \mathrm{dy})$, with its reciprocal, $\mathrm{r}$, being interpreted as the utility marginal cost, $\mathrm{r}=\mathrm{dy} / \mathrm{du}$, or as a utility hypothetical price. Given that $\mathrm{u}(\mathrm{q})$ is strictly quasi-concave, the system:

$$
\mathrm{u}_{\mathrm{i}}(\mathbf{q})=\lambda \mathrm{p}_{\mathrm{i}}=\frac{\mathrm{p}_{\mathrm{i}}}{\mathrm{r}}
$$

could be inverted, obtaining $q_{i}=f_{i}(\mathbf{p}, r)(i=1, \ldots, n)$. Frisch (1932) used a version of this system in the framework of additive preferences to measure the money marginal utility and, for this, following Browning (1982), we call these the Frischian Demand Functions.

According to these functions, the demanded quantities of goods in equilibrium depend on prices and the marginal cost of the utility (inverse of the income marginal utility). The notion is that the consumer is compensated by changes in prices with enough money to keep the marginal utility of income constant at its initial level. This concept is particularly useful in the intertemporal context, given that a primary objective of rational individuals during the life cycle is to maintain constant their marginal utility of income, obviously, in discounted terms. That is to say, in the context of perfect information about the future, the Frischian demands describe the consumption behaviour of individuals in terms of the current prices and on the marginal utility of income $r$, which, being constant, includes all the known, relevant, extra-period information in the decision process. In other words, the individual must always maintain constant during his/her life cycle the utility derived from current income, in discounted terms.

Knowing that $r$ is the utility marginal cost, I can obtain from the Frischian demands in an alternative way. To that end, I consider the isomorphism previously indicated in the production theory and we suppose that the consumer uses certain inputs, goods, to obtain an output, utility, whose price is $r$. In this exposition, I can define the Profit Function in Consumption as the maximum profit that the agent can attain when "selling" own utility at the price r, given the utility function and good prices. For a general function $u=u(q)$ strictly concave, the appropriate benefit function will be given by:

$$
\pi(\mathbf{p}, \mathrm{r})=\operatorname{Max}_{\mathrm{u}, \mathrm{q}}\{\mathrm{r} \mathrm{u}-\mathbf{p q} ; \mathrm{u}=\mathrm{u}(\mathbf{q})\}
$$


which is continuous, convex, linear homogeneous in $\mathbf{p}$ and $r$, increasing in $r$, decreasing in $\mathbf{p}$ and, finally, it "inherits" separability from the Utility Function. An alternative form of expressing the benefit function is in terms of the expenditure function, that is to say:

$$
\pi(\mathbf{p}, \mathrm{r})=\operatorname{Max}_{\mathrm{u}}\{\mathrm{r} \mathrm{u}-\mathrm{c}(\mathbf{p}, \mathrm{u})\}
$$

From this function and making use of the Hotelling theorem, I can derive the demanded quantities of each good in equilibrium and, additionally, I can also derive the utility in terms of the good prices and the price of utility:

$$
\begin{gathered}
-\pi_{\mathrm{i}}(\mathbf{p}, \mathrm{r})=\mathrm{q}_{\mathrm{i}}=\mathrm{f}_{\mathrm{i}}(\mathbf{p}, \mathrm{r}) \quad(\mathrm{i}=1, \ldots, \mathrm{n}) \\
\pi_{\mathrm{r}}(\mathbf{p}, \mathrm{r})=\mathrm{u}
\end{gathered}
$$

The functions qi $=f i(p, r),(i=1, \ldots, n)$, show the quantities of the goods that are going to be demanded to achieve a determined level of income marginal utility (or utility marginal cost), with constant prices, in such a way that the benefit from consumption is the maximum possible.

\section{Alternative expressions of the Substitution Effect}

I now develop two alternative expressions of the Substitution Effect from the relationships among the Marshallian, Hicksian, and Frischian demand functions.

\section{Proposition 1}

The Substitution Effect can be expressed in terms of the derivatives of the Profit Function in Consumption:

$$
\mathrm{S}_{\mathrm{ij}}=-\pi_{\mathrm{ij}}+\frac{\pi_{\mathrm{ir}} \pi_{\mathrm{jr}}}{\pi_{\mathrm{rr}}}
$$

Proof. From the Slutsky Equation, $\mathrm{S}_{\mathrm{ij}}=\mathrm{T}_{\mathrm{ij}}-\mathrm{R}_{\mathrm{ij}}$, and using the Hotelling theorem:

$$
\mathrm{S}_{\mathrm{ij}}=\frac{\partial \mathrm{q}_{\mathrm{i}}}{\partial \mathrm{p}_{\mathrm{j}}}+\mathrm{q}_{\mathrm{j}} \frac{\partial \mathrm{q}_{\mathrm{i}}}{\partial \mathrm{y}}=\frac{\partial \mathrm{q}_{\mathrm{i}}}{\partial \mathrm{p}_{\mathrm{j}}}+\frac{\partial \mathrm{c}}{\partial \mathrm{p}_{\mathrm{j}}} \frac{\partial \mathrm{q}_{\mathrm{i}}}{\partial \mathrm{y}}
$$

Now assuming that income is equal to expenditure and operating:

$$
\mathrm{S}_{\mathrm{ij}}=\frac{\partial \mathrm{q}_{\mathrm{i}}}{\partial \mathrm{p}_{\mathrm{j}}}+\frac{\partial(\partial \mathrm{y} / \partial \mathrm{u})}{\partial \mathrm{p}_{\mathrm{j}}} \frac{\partial \mathrm{q}_{\mathrm{i}}}{\partial(\partial \mathrm{y} / \partial \mathrm{u})}
$$

Given that $\mathrm{c}(\mathbf{p}, \mathrm{u})=\operatorname{Max}_{\mathrm{r}}\{\mathrm{r} \mathrm{u}-\pi(\mathbf{p}, \mathrm{r})\}$ and, therefore, $\delta \mathrm{y} / \delta \mathrm{u}=\mathrm{r}$, knowing that $-\pi_{\mathrm{i}}(\mathbf{p}, \mathrm{r})=$ $\mathrm{q}_{\mathrm{i}}$ and operating:

$$
\mathrm{S}_{\mathrm{ij}}=-\frac{\partial \pi_{\mathrm{i}}}{\partial \mathrm{p}_{\mathrm{j}}}+\frac{\partial(\partial \mathrm{y} / \partial \mathrm{u})}{\partial \mathrm{p}_{\mathrm{j}}}\left(-\frac{\partial \pi_{\mathrm{i}}}{\partial \mathrm{r}}\right)=-\pi_{\mathrm{ij}}+\frac{\partial\left(\partial \mathrm{c} / \partial \mathrm{p}_{\mathrm{j}}\right)}{\partial \mathrm{u}}\left(-\pi_{\mathrm{ir}}\right)=-\pi_{\mathrm{ij}}=-\pi_{\mathrm{ij}}+\frac{\partial \mathrm{q}_{\mathrm{j}}}{\partial \mathrm{r}} \frac{\partial \mathrm{r}}{\partial \mathrm{u}}\left(-\pi_{\mathrm{ir}}\right)
$$

And, finally, given that $\pi(\mathbf{p}, \mathrm{r})=\mathrm{ru}(\mathrm{r})-\mathrm{c}(\mathbf{p}, \mathrm{u})$ and, consequently:

$$
\frac{\partial \pi}{\partial r}=\pi_{r}=u(r)+r \frac{\partial u}{\partial r}-\frac{\partial c}{\partial r}=u(r)+r \frac{\partial u}{\partial r}-\frac{\partial y}{\partial u} \frac{\partial u}{\partial r}=u
$$

then:

$$
S_{\mathrm{ij}}=-\pi_{\mathrm{ij}}+\frac{\partial \mathrm{q}_{\mathrm{j}}}{\partial \mathrm{r}} \frac{\partial \mathrm{r}}{\partial \mathrm{u}}\left(-\pi_{\mathrm{ir}}\right)=-\pi_{\mathrm{ij}}+\left(-\pi_{\mathrm{jr}}\right) \frac{\partial \mathrm{r}}{\partial \pi_{\mathrm{r}}}\left(-\pi_{\mathrm{ir}}\right)=-\pi_{\mathrm{ij}}+\frac{\pi_{\mathrm{ir}} \pi_{\mathrm{jr}}}{\pi_{\mathrm{rr}}}
$$


with the two terms on the right side being the specific and general substitution effects (Houthakker, 1960). If $\pi_{\mathrm{ij}}<0$ ( $>0$ ) I call $\mathrm{i}$ and $\mathrm{j}$ specific substitutes (complements), with the first case indicating that the demand for good $\mathrm{i}$ rises following a price rise for good $\mathrm{j}$ and $\mathrm{a}$ change in income that keeps the marginal utility of income constant. $\bullet$

Probably, the best application of the fact that the Profit Function of Consumption "inherits" separability from the Utility Function is the inter-temporal analysis, given that we often assume inter-temporal separability. The importance of the Frischian demands in this inter-temporal context derives from the fact that, with perfect certaintly, $r$ is a "sufficient" statistic for all extraperiod information.

\section{Proposition 2}

In the inter-temporal context with perfect certainty, the Substitution Effect can be expressed in terms of the inter-temporal substitution elasticity

$$
\stackrel{\vee}{\omega}^{-1}=\frac{\partial \log y}{\partial \log r}
$$

which denotes the change in expenditure needed to keep constant the marginal utility of income, and whose inverse is the Money Flexibility concept of Frisch (1959):

$$
\mathrm{S}_{\mathrm{ij}}=\mathrm{f}_{\mathrm{ij}}+\mathrm{y \omega} \omega^{-1} \frac{\partial \mathrm{q}_{\mathrm{i}}}{\partial \mathrm{y}} \frac{\partial \mathrm{q}_{\mathrm{j}}}{\partial \mathrm{y}}
$$

Proof. My starting point in the previous demonstration,

$$
\mathrm{S}_{\mathrm{ij}}=-\pi_{\mathrm{ij}}+\frac{\pi_{\mathrm{ir}} \pi_{\mathrm{jr}}}{\pi_{\mathrm{rr}}}
$$

and given that $-\pi_{i}(\mathbf{p}, r)=q_{i}=f_{i}(\mathbf{p}, r)$ :

$$
-\pi_{\mathrm{ij}}=-\frac{\partial^{2} \pi}{\partial \mathrm{p}_{\mathrm{i}} \partial \mathrm{p}_{\mathrm{j}}}=\frac{\partial \mathrm{f}_{\mathrm{i}}}{\partial \mathrm{p}_{\mathrm{j}}}=\mathrm{f}_{\mathrm{ij}}
$$

Also, given that: $\pi_{\mathrm{i}}(\mathbf{p}, \mathrm{r})=-\mathrm{q}_{\mathrm{i}}$ and that $\pi_{\mathrm{r}}(\mathbf{p}, \mathrm{r})=\mathrm{u}$ :

$$
\frac{\pi_{\mathrm{ri}} \pi_{\mathrm{rj}}}{\pi_{\mathrm{rr}}}=\frac{\frac{\partial^{2} \pi}{\partial \mathrm{r} \partial \mathrm{p}_{\mathrm{i}}} \frac{\partial^{2} \pi}{\partial \mathrm{r} \partial \mathrm{p}_{\mathrm{j}}}}{\frac{\partial^{2} \pi}{\partial \mathrm{r}^{2}}}=\frac{\left(-\frac{\partial \mathrm{q}_{\mathrm{i}}}{\partial \mathrm{r}}\right)\left(-\frac{\partial \mathrm{q}_{\mathrm{j}}}{\partial \mathrm{r}}\right)}{\frac{\partial \mathrm{u}}{\partial \mathrm{r}}}
$$

and now operating and given that $\frac{\partial y}{\partial u}=r$ :

$$
\frac{\partial \mathrm{q}_{\mathrm{i}}}{\partial \mathrm{y}} \frac{\partial \mathrm{y}}{\partial \mathrm{r}} \frac{\partial \mathrm{q}_{\mathrm{j}}}{\partial \mathrm{y}} \frac{\partial \mathrm{y}}{\partial \mathrm{r}} \frac{\partial \mathrm{r}}{\partial \mathrm{y}} \frac{\partial \mathrm{y}}{\partial \mathrm{u}}=\frac{\partial \mathrm{q}_{\mathrm{i}}}{\partial \mathrm{y}} \frac{\partial \mathrm{q}_{\mathrm{j}}}{\partial \mathrm{y}} \frac{\partial \mathrm{y}}{\partial \mathrm{r}} \mathrm{r} \frac{\mathrm{y}}{\mathrm{y}}=\frac{\partial \mathrm{q}_{\mathrm{i}}}{\partial \mathrm{y}} \frac{\partial \mathrm{q}_{\mathrm{j}}}{\partial \mathrm{y}} \omega^{-1} \mathrm{y}
$$

Thus:

$$
S_{i j}=-\pi_{i j}+\frac{\pi_{i r} \pi_{j r}}{\pi_{r r}}=f_{i j}+\frac{\partial q_{i}}{\partial y} \frac{\partial q_{j}}{\partial y} \omega^{-1} y
$$

where the first term on the right side denotes the intra-temporal Frischian substitution effect, and the second term is a general substitution effect expressed in terms of the inter-temporal 
elasticity of substitution. The intra-temporal effect can be positive or negative, in such a way that goods can be specific substitutes or complements (it is well known that in a two-good system, they cannot be complements from the Hicksian Substitution Effect $S_{i j}$ ), whereas the inter-temporal will be negative for normal goods since the inter-temporal elasticity of substitution is negative for a strictly concave Utility Function.

\section{Conclusions}

This paper has developed two alternative theoretical expressions of the Substitution Effect derived from the relationships among the Marshallian, Hicksian, and Frischian demand functions. In particular, I use the Profit Function in Consumption as the Income Flexibility of Frisch, in order to derive alternative expressions of the SE.

I work in the context of perfect information about the future, that is to say, assuming anticipated changes, in such a way that the marginal utility of income is constant, thus including all the known, relevant, extra-current information in the decision process. However, it is usual that individuals decide in an environment of uncertainty where individuals will have, as time goes on, new information that they must incorporate to the marginal utility of income, thus modifying it successively. A clear extension of my work is to derive the alternative theoretical expressions of the SE in this uncertainty context where changes are un-anticipated.

\section{Acknowledgements}

I would like to express my gratitude to José Alberto Molina, for helping me in the development of the theoretical framework.

\section{References}

Altonji, J. G. (1986) Intertemporal substitution in labor supply: evidence from micro data, Journal of Political Economy, 94, S176-S215.

Ashenfleter, O., and Heckman, J. J. (1974) The Estimation of Income and Substitution Effects in a Model of Family Labor Supply, Econometrica, 42, 73-85.

Becker, G. (1976) The Economic Approach to Human Behavior, The University of Chicago Press.

Browning, M. (1982) Profit function representations for consumer preferences, Bristol University Discussion Paper No 82/125.

Brandt, L., Siow, A., and Wang, J. (2013) Substitution effects in parental investments, Journal of Population Economics, 28, 423-462.

Frisch, R. (1932) New Methods of Measuring Marginal Utility, Verlag Von J. C. B. Mohr, Tübingen.

Frisch, R. (1959) A complete scheme for computing all direct and cross demand elasticities in a model with many sectors, Econometrica 27, 177-196.

Houthakker, H. S. (1960) Additive preferences, Econometrica, 28, 244-256.

Manoli, D., and Weber, A. (2010) Intertemporal substitution in labor force participation: evidence from policy discontinuities, IZA Discussion Paper No. 5248.

Molina, J. A. (2011) Household Economic Behaviors, Springer.

Sproule, R. (2013) A systematic analysis of the link amongst the Marshallian, Hicksian, and Frischian demand functions: A note, Economic Letters, 121, 555-557. 